\section{Pyroelectric $\mathrm{LiNbO}_{3}$ Crystals Emit Self-Focusing Electron Beam}

Pyroelectric crystals-crystals that become electrically charged on heating or cooling _ emit self-focusing, spatially stable electron beams with energies of up to $170 \mathrm{keV}$ when heated in the $100-200^{\circ} \mathrm{C}$ range and cooled to room temperature. According to researchers J.D. Brownridge of the State University of New YorkBinghamton and S.M. Shafroth of the University of North Carolina-Chapel Hill, electron beams with focal lengths of 17-22 $\mathrm{mm}$ were achieved by varying the thickness of the crystal. Brownridge said that this finding, which was reported in the November 12 issue of Applied Physics Letters, "allows us to replace-in some cases-the radioactive sources that are now used to excite elements in x-ray fluorescence spectrometers."

While pyroelectricity is a well-known phenomenon used to produce sensitive devices for infrared detection and photonics, the emission of a focused electron beam had been overlooked until now. This is probably because at atmospheric pressure, the negatively polarized surface produced by the heating/cooling sequence is quickly neutralized by bombardment with positive ions present in the atmosphere. By maintaining pressures as low as 0.5 mTorr during the process, the surface charge can be maintained for hours, permitting the electron-beam phenomenon to be observed. Surface electrical-field lines are slightly inclined toward the axis of the crystal, which accounts for the focusing phenomenon.

Samples were prepared by cutting the $\mathrm{LiNbO}_{3}$ crystal perpendicular to its threefold rotationally symmetric $z$ axis. By resistively heating the $+z$ base of the crystal, the opposite $-z$ base becomes positively charged; upon cooling, the $-z$ base switches to a negatively charged state. When a cylindrical sample $5 \mathrm{~mm}$ in diameter and $5 \mathrm{~mm}$ thick was heated to $115^{\circ} \mathrm{C}$ in a $<10$ mTorr nitrogen atmosphere, a spatially stable, focused electron beam was observed on a $\mathrm{ZnS}$ screen placed $17 \mathrm{~mm}$ away when the sample reached room temperature. By repeating the experiment with pressures ranging from $0.5 \mathrm{mT}$ Torr to $8 \mathrm{mT}$ Torr, the investigators found that the electron beam became brighter and more diffuse with increasing pressure; at $8 \mathrm{mTorr}$, the electron beam "blew up," and its intensity dropped to zero.

A cylindrical sample of the crystal $4 \mathrm{~mm}$ in diameter and $10 \mathrm{~mm}$ thick produced an electron beam with a focal length of $22 \mathrm{~mm}$ and a spot size of $1 \mathrm{~mm}$. A surface-barrier electron detector installed in place of the $\mathrm{ZnS}$ screen measured electron energies as high as $170 \mathrm{keV}$ at room temperature for a sample that had been heated to $160^{\circ} \mathrm{C}$. The beam energy decreased nearly exponentially with time after reaching room temperature, but was still emitting $20-\mathrm{keV}$ electrons after $5 \mathrm{~h}$.

Brownridge and Shafroth said that several x-ray fluorescence spectrometers using pyroelectric crystals as electron sources are already in operation in their research group. As a radiation safety officer at Binghamton, Brownridge particularly likes the safety of these crystals over standard radioactive sources. "If a student took out one of these crystals and accidentally put it in his pocket," he said, "it would not be a problem."

TIM PALUCKA

\section{STM Enables Study of CO Oxidation Mechanisms on a Metal Surface}

While studying the mechanism of $\mathrm{CO}$ oxidation on a $\operatorname{Ag}(110)$ surface, Professor W. Ho and graduate student J.R. Hahn from the University of California-Irvine determined the presence of a previously proposed $\mathrm{O}-\mathrm{CO}-\mathrm{O}$ intermediate species in the production of $\mathrm{CO}_{2}$. The formation of $\mathrm{CO}_{2}$ by the catalytic oxidation of $\mathrm{CO}$ at metal surfaces is important as a model for heterogeneous catalysis. According to Ho, the researchers were able to obtain their results by combining imaging, manipulation, and spectroscopic capabilities: They monitored the interaction of $\mathrm{CO}$ molecules with $\mathrm{O}$ atoms by scanning tunneling microscopy (STM) and vibrational analysis of CO by inelastic electron tunneling spectroscopy with the STM (STM-IETS). Ho said that this combination "allowed for direct visualization of reaction pathways at the single-molecule level."

As reported in the October 15 issue of Physical Review Letters, the researchers used a home-built variable-temperature STM to carry out the measurements. The $\mathrm{Ag}(110)$ substrate was cleaned by $\mathrm{Ne}$-ion sputtering and annealed at $693 \mathrm{~K}$. The STM tip was prepared from polycrystalline tungsten wire and cleaned by Ne-ion sputtering. The $\mathrm{O}_{2}$ molecules ( $<0.01$ monolayer) were adsorbed at $45 \mathrm{~K}$ by a capillary doser to ensure molecular chemisorption. The CO molecules ( $<0.001$ monolayer) were adsorbed at $13 \mathrm{~K}$. The $\mathrm{O}$ atoms were generated by dissociating $\mathrm{O}_{2}$ molecules with tunneling electrons from the STM tip. All experiments were carried out at $13 \mathrm{~K}$.

According to their report, the $\mathrm{O}-\mathrm{CO}-\mathrm{O}$ intermediate complex was formed by bringing a $\mathrm{CO}$ molecule in close proximity to a pair of nearest-neighbor $\mathrm{O}$ atoms. The complex was formed whether this transfer was accomplished by lateral movement of adsorbed CO across the surface or by a direct transfer of a $\mathrm{CO}$ molecule from the STM tip above the surface, they said. An electron pulse over the $\mathrm{CO}$ in this complex resulted in the production and desorption of a $\mathrm{CO}_{2}$ molecule. STM-IETS data shows an increase in the vibrational energy of the $\mathrm{CO}$ molecule in the intermediate relative to adsorbed free CO. This data, they said, in conjunction with theoretical calculations, indicates that the interaction of the $\mathrm{O}$ atom with the $\mathrm{CO}$ molecule results in a weakening of the $\mathrm{O}-\mathrm{Ag}$ bond and the formation of an $\mathrm{O}-\mathrm{CO}$ bond. The spatial distribution of the $\mathrm{CO}$ vibrational intensity in the complex provides a direct view of its structure.

The formation of an intermediate complex was not observed if the $\mathrm{CO}$ was brought in close proximity to $\mathrm{O}$ atoms that were farther apart than nearest neighbors. In such cases, the researchers said, $\mathrm{CO}_{2}$ production could only be induced if the $\mathrm{CO}$ was released from the STM tip above an $\mathrm{O}$ atom. No reaction was observed when the STM tip with an adsorbed $\mathrm{CO}$ molecule was simply brought in contact with the adsorbed $\mathrm{O}$ atoms. The production of $\mathrm{CO}_{2}$ was not observed between $\mathrm{CO}$ and molecular $\mathrm{O}_{2}$.

GREG KHITROV

\section{Theoretical Calculations Predict that $\mathrm{H}^{+}$Causes Direct Depassivation of Si-H Bonds}

One question facing the microelectronics industry deals with the control of the surface/interface properties of silicon. In particular, the study of $\mathrm{Si}-\mathrm{SiO}_{2}$ interfaces and how the introduction of a proton increases the quality of such interfaces is important. $\mathrm{H}$ is essential to passivate dangling bonds in order to produce high quality interfaces. A computational study was recently reported on this topic by researchers at Vanderbilt University in Nashville, Tenn. and Oak Ridge National Laboratory. In the October 15 edition of Physical Review Letters, these researchers introduced results demonstrating the interaction of protons with a (001) $\mathrm{Si}-\mathrm{SiO}_{2}$ interface. The researchers found that the depassivation of dangling $\mathrm{Si}$ bonds was due not to the dynamics of Si electrons and space charge regions, but instead to the ability of $\mathrm{H}^{+}$to easily diffuse throughout the interfacial plane and that important depassivation of $\mathrm{Si}-\mathrm{H}$ bonds occurs by the reaction

$$
\mathrm{Si}-\mathrm{H}+\mathrm{H}^{+} \rightarrow \mathrm{D}^{+}+\mathrm{H}_{2}
$$

where $\mathrm{D}$ is a dangling bond. After this process, the positively charged dangling bonds freely interact with $\mathrm{Si}$ electrons. The researchers used calculations based upon density-functional theory (DFT), local-density approximations for exchange correla- 
tion, ultrasoft pseudopotentials, supercells, and plane waves. In particular, supercells or "superstructures" of $\mathrm{Si}-\mathrm{SiO}_{2}-\mathrm{Si}$ with 7-8 planes of $\mathrm{Si}$ layers separating the $\mathrm{SiO}_{2}$ layers were used. The researchers concluded that $\mathrm{H}^{+}$is the only charged state in the supercell because all positively charged defects were more stable than their neutral states by $\sim 3 \mathrm{eV}$ when their Fermi energy approached the top of the $\mathrm{Si}$ valence band. The researchers found that as an $\mathrm{H}^{+}$atom approaches the interface, it is repelled by other $\mathrm{H}^{+}$atoms, and either is immediately trapped inside a suboxide bond or $\mathrm{SiO}_{2}$ protrusion, or migrates laterally throughout the supercell with energy barriers of $0.3-0.5 \mathrm{eV}$, with the barriers for leaving the cell being much larger. The research team also calculated how the reaction between $\mathrm{H}^{+}$and Si-H defects occurs mechanistically. As $\mathrm{H}^{+}$comes within $1.6 \AA$ of the $\mathrm{Si}-\mathrm{H}$ bond, a $\mathrm{H}^{+}-\mathrm{H}-\mathrm{Si}$ bridge forms, followed by release of $\mathrm{H}_{2}$ and the formation of a positive defect $\left(\mathrm{D}^{+}\right)$. This was shown with electron-density plots. These plots, according to the research team, show the depassivation process as $\mathrm{H}^{+}$approaches the $\mathrm{Si}-\mathrm{H}$ bond, bridge formation, and subsequent defect formation. Total energies released from this reaction were $1.3 \mathrm{eV}$, but the cost for the reaction was $1.6 \mathrm{eV}$. According to the report, this reaction was also found to be reversible with annealing in $\mathrm{H}_{2}$ to show an energy barrier of $1.6 \mathrm{eV}$.

MATHEW M. MAYE

\section{Large Ordered Arrays of Si Nanocrystals Achieved by Controlled Template Nucleation}

The process of self-ordering nucleation of nanocrystals was previously demonstrated by using strained layers in non-latticematched systems and by chemically employing two-dimensional (2D) polymer matrices. A research group headed by Philippe Fauchet and Leonid Tsybeskov at the University of Rochester and Q. Xie from Semiconductor Product Sector in Mesa, Ariz. have demonstrated a way of managing silicon nucleation by facilitating the long-range ordering of uniformly sized and shaped nanocrystals through a controlled template. As reported in the November issue of Nano Letters, the research team used inverse-pyramidshaped holes with submicrometer 2D periodicity to control the in-plane properties of the crystals. The $a-\mathrm{Si} / \mathrm{SiO}_{2}$ superlattices were deposited by sputtering and crystallized by high-temperature rapid thermal annealing (RTA) on this template.

Using maskless interferometric photolithography and reactive-ion etching, a periodic array of holes was transferred to an underlying oxide layer. Anisotropic $\mathrm{KOH}$ etching on exposed (100) Si was used to form an inverted pyramid due to a high etch ratio of (100) surfaces over (111) planes. Etching was carried out at $70^{\circ} \mathrm{C}$ for $3 \mathrm{~min}$ using a dilute $(25 \%) \mathrm{KOH}$ solution, yielding holes shaped like inverted pyramids with atomically smooth (111) walls. A 10-period $a-\mathrm{Si} / \mathrm{SiO}_{2}$ superlattice was grown on the predefined template by sputtering in the presence of alternate $\mathrm{Ar} / \mathrm{Ar}+\mathrm{O}_{2}$ plasma. Using a $\mathrm{Si}$ target, the researchers made films with a final thickness of $50 \AA$ for the $a$-Si layers and $30 \AA$ for the $\mathrm{SiO}_{2}$ layers. They said that transmission electron micrographs revealed the continuity of the film through the transition from the wafer surface to the sidewall, although gradual thinning along the pyramid's walls was also observed.

The nucleation process was carried out at $900^{\circ} \mathrm{C}$ for $30 \mathrm{~s}$, using an RTA oven, a typical initiation step for the crystallization of amorphous silicon. According to the researchers, isolated, regularly sized and shaped silicon nanoclusters formed at or

\section{MRS special delivery}

Let MRS bring materials information to you: Sign up for any of these FREE services today!

\section{Publications Alert \\ mrs-pubs-alert-subscribers@mrs.org}

Review tables of contents in advance for the MRS Bulletin and Journal of Materials Research.

NEW! MRS E-News

mrs-enew-subscribe@mrs.org

Receive a monthly "e-newsletter" on the latest new research highlights, professional opportunities, and other materials information.

NEW! Women in MS\&E

mrs-women-subscribe@mrs.org

Join a mailing list for discussion and information exchange on issues affecting women in the materials profession. Women and men welcome to participate.

MRS Public Affairs Alert

mrs-publicaffairs-subscribe@mrs.org

Receive concise summaries of current public policy issues affecting materials science and engineering and learn what actions you can take to make a difference.

\section{www.mrs.org...the Materials Gateway}

